\title{
Reviews
}

Frederick Williams and David Gibson (Editors), Technology Transfer: A Communication Perspective. (London: Sage, 1990, Softback, 302 pp.)

Technology transfer is an interdisciplinary subject, with almost as many definitions of technology in the literature as there are contributions to the field. This book, however, succeeds in identifying a characteristic which underpins all such transactions, the view of technology as information and technology transfer as a 'communication system', thus presenting a coherent framework within which to view a diverse and complex subject.

Each chapter in the book is written by a separate author, the first of which sets the context by establishing the importance of technology as an economic resource in today's global marketplace. The following section then presents conceptual schemes and analytical tools with which to study the subject, for example, by defining networks of organisations involved in technology transfer, from which to evaluate the stability and power relationships within and between the participants.

The third section of the book considers mainly vertical types of transfer involving the movement of technology from one stage of the research and development process to another, generally spanning the continuum from basic research, through invention, innovation, and diffusion. Various contexts in which technology is developed and transferred are presented, including R \& D consortia, and university-industry relationships, which sometimes generate spin-off ventures. Throughout this section, the importance of people is emphasised, showing how each participant's experience and goals in the project influence the outcome of the group. The importance of the synergy between participant organisations (e.g. university, industry, government agencies, $\mathrm{R} \& \mathrm{D}$ institutes) in the

IOS Press

Human Systems Management 10 (1991) 233-235 transfer process is also highlighted.

The focus of the book then broadens to a consideration of international, horizontal flows of technology, involving the use of systems and methods in one culture that were developed for application in a different culture. These studies show how technology transfer can go beyond the transfer of individuals and hardware, to include transfer of organisational structures, work environments, and managerial innovations. These studies also touch on the economic, social and political ramifications of international technology transfer.

Throughout the book, there is an emphasis on the importance of people and the exchange of information within the transfer process. The book is geared more toward the serious scholar of technology transfer and organisational forms, with its presentation of conceptual frameworks and analytical tools, although there are also some interesting empirical findings, for example, describing the maquiladora industries in the US and Mexico, Japan's Science City, and Anderson Consulting's corporate training practices, which may also be of interest to the industrial practitioner.

Overall, the book presents a clear message of the importance of technology, and the relationships and linkages needed to support a sound technological base which countries need to develop and maintain in the increasingly competitive global economy. The conceptual theme presented throughout the book of technology transfer as a communication process is a good one, which could perhaps be further developed and presented more cohesively in a volume consisting of less diverse, individual contributions. The current book, however, serves to highlight the application and inter-relationship of this theme to the wide ranging concerns of technology transfer.

Carol L. LEGG

University of Cambridge 
John Hagedoorn, The Dynamic Analysis of Innovation and Diffusion: A Study in Process Control (Pinter Publishers, London, 1989, pp 197).

Few would fail to credit Marx as one of the first to recognise the importance of technological development in the evolution of capitalism. It is no surprise therefore that in rethinking the development of new technologies and their relationship to industrial structures this book should seek new millage in the work of Marx, and the economist who shared many ideas with him, Schumpeter.

In criticising certain contemporary frameworks, the author calls for wider scope to be given to the subject of innovation and diffusion. Suggested is an approach which focuses on technological change and its dialectical relation to changes in industrial structures. An analytical framework is developed which is used in an empirical enquiry in to process control technology. It reflects an approach to innovation based on an evolutionary stance, in which technological development are examined in terms of technological trajectories, basic designs and technological paradigms. The approach detailed takes innovation to be a largely endogenous factor, with economic disequilibrium, asymmetries of companies and changes in technology and industrial structures considered within the theoretical frame.

In chapter 2 , the theoretical background to the subject is explored, concentrating on the work of Marx and Schumpeter. Attention is placed on the roles that different categories of companies play in innovation, as well as the role of monopoly in technological change.

In chapter 3 , the ideas developed in the previous chapter are explored and an attempt is made to overcome their endemic limitations with the aid of the author's emendation. The relationship which company size, monopoly capital and innovation play in innovation and diffusion are then addressed. In examining this, a dynamic interpretation is used, together with empirical conclusions, and extended into the new theoretical framework.

Chapters 4 and 5 focus on technological development. The analytical framework is developed and the empirical research, based upon an international survey of the process control industry, is discussed.
The book then attempts to glean an understanding of technology and technological opportunity, allowing technical change to be analysed in terms of best practice technologies and of patterns of diffusion. The character of industrial change is then examined, focusing on the role of different categories of companies in generating innovation and change. Attention is also addressed to the content of innovation strategies with respect to technological developments.

Within the process control industry, the author notes a change in technological paradigm over recent decades following the introduction of computer control. Quite rightly, considerable importance is placed on the careful selection of indicators in assessing innovation in companies. True to the credo of Marx, emphasis is placed on an understanding of the technology itself in grasping the dynamics of change. The book concludes that more attention should be placed on developing interdisciplinary research to provide better analytical tools with which to understand economic and technological development.

It can certainly be said that this book suggests a useful direction in which theoretical and empirical work might turn, watching technological development unfold within certain technological paradigms. It suggests that attention to be paid to the role of different categories of companies in the world of competition and changing industrial structures, thus broadening the research horizons of innovation theory. Although the sector studied precludes generalization of the empirical findings, the call for a more multi-disciplinary approach can certainly be addressed elsewhere.

\section{Paul J. JACKSON}

University of Cambridge

Malcolm Warner, Werner Wobbe and Peter Brodner (Editors), New Technology and Manufacturing Management: Strategic Choices for Flexible Production Systems. (John Wiley, Chichester, 1990, $267 \mathrm{pp})$.

The arrival of the micro-processor in manufacturing may well have been the death-knell for the 
days of Fordist-type production. Computer Integrated Manufacturing now offer companies new choices of organisation and resourcing. In this new era, we find ourselves at a juncture where technocentric rationales of organisation well may be turned on their head in favour of the primacy of human resources. In manufacturing management today, one particular vogue term is that of 'flexibility'. What this actually means for organisations is dealt with in this book. The authors move from a discussion of the forces and choices facing today's factories through to an analysis of what this may mean for the factory of tomorrow, suggesting how strategy can be evolved to glean the most from the new age of manufacturing.

The book is presented in four main parts. Chapters 1 to 5 examine the trends towards the flexible factory. The dynamics of environmental turbulence and technological development are examined. The effect of information technologies on integrating manufacturing is examined together with the increase in automation technologies. Whilst it is suggested that the unmanned factory is unlikely to emerge in the near future, the need for new perspectives in planning which integrate functional perspectives is clearly enunciated. Although no common model for design of new factory systems is suggested, it is clear here that the factory of tomorrow will not be designed on purely bureaucratic, functional lines. Moreover, it is suggested that the building-blocks of tomorrows organisations will have to be the skills and resources of the workers themselves. The implications this may have for job profiles and training needs are given considerable detail.

Chapters 6 to 10 examine the conditions necessary to facilitate flexible production. The diffusion of new technologies are discussed and the means by which these may be integrated into organisations are explored. A clarion call for skill-based manufacture is made here, noting the cultural problems this may create for firms locked in to technocentric orientations. It is suggested that new skills and new strategies need to be developed in order to find the optimum way to draw together human and technical resources.

Chapters 11 to 15 outline a number of European perspectives. Better and more widespread vocational training and education at all levels are called for in order to create the necessary skills, but especially to engender the attitudes and orientations that will be necessary to support new organisation forms. A final plea is made for manufacturers of Western Europe not to adopt a US type model but to develop the human-centred approach advocated throughout the book.

The concluding chapters focus on the need to develop strategies to ensure the aforementioned policies can be executed. The need to concentrate education among decision makers is suggested. The book concludes that to manage the computer integrate manufacturing organisational forms will have to emerge, based on a 'culture of permanent implementation'.

The papers set out in this book present a clear and coherent set of ideas which few people engaged in manufacturing management can afford to ignore. A convincing set of arguments are built up from an analysis of the problems facing many European manufacturers, and the solutions open to them are teased out and explored. It is a largely optimistic set of work which suggests that a more human-centred approach will not only bring greater personal rewards for those engaged in manufacture, but is also the most attractive economic option. However, the possibilities for a polarisation between highly skilled and unskilled workers is mentioned, a factor which education and training may however keep check. By its very ethos, it is a work that should interest all functional areas of the organisation, and importantly, educationalist wishing to fulfil the didactic side of securing the skills and attitudes called for.

Paul J. JACKSON

University of Cambridge 